\title{
Performance Evaluation of Finite Queue Switching Under Two-Dimensional M/G/1(m) Traffic
}

\author{
Md. Syeful Islam*, Md. Rezaur Rahman*, Anupam Roy*, Md. Imdadul Islam* \\ and M. R. Amin**
}

\begin{abstract}
In this paper we consider a local area network (LAN) of dual mode service where one is a token bus and the other is a carrier sense multiple access with a collision detection (CSMA/CD) bus. The objective of the paper is to find the overall cell/packet dropping probability of a dual mode LAN for finite length queue $\mathrm{M} / \mathrm{G} / 1(\mathrm{~m})$ traffic. Here, the offered traffic of the LAN is taken to be the equivalent carried traffic of a one-millisecond delay. The concept of a tabular solution for two-dimensional Poisson's traffic of circuit switching is adapted here to find the cell dropping probability of the dual mode packet service. Although the work is done for the traffic of similar bandwidth, it can be extended for the case of a dissimilar bandwidth of a circuit switched network.
\end{abstract}

Keywords-Carried Traffic, LST, Two-Dimensional Traffic, Cell Dropping Probability, M/G/1 Model

\section{INTRODUCTION}

In many communication systems, two or more traffic links are usually merged together to form a common trunk line or different types of traffic may share the bus or ring of a local area network (LAN). If a communication network is in statistical equilibrium and serving two or more different types of traffic, it can be modeled by the help of a multi-dimensional state transition diagram. The transmission of real time data, like audio or video, which needs a constant arrival rate in sequential order to play the signal instantly at the receiving end requires circuit switching. On the other hand, packet switching is more efficient for data, which can withstand delays (such as e-mails, word files, etc.). For example, if any link experiences two types of Poisson's offered traffic $A_{1}$ and $A_{2}$, then a two-dimensional Markov chain is considered as the simplest solution. The solution of the two-dimensional Markov chain (both similar and dissimilar bandwidth traffic) can be obtained in tabular form [1-3] for a limited trunk case. A good example of multidimensional traffic is the mobile cellular network, where two different arrivals, (i.e., new originating and handoff arrival traffic) are prevalent, as summarized in [4-6], where the bandwidth of both the traffic is the same since both are voice signals. If there is a provision of another offered traffic of a different bandwidth, say, if video/text/image data is added with the

\footnotetext{
Manuscript received May 26, 2011; first revision October 5, 2011; accepted October 27, 2011.

Corresponding Author: M. R. Amin

* Department of Computer Science and Engineering, Jahangirnagar University, Savar, Dhaka 1342, Bangladesh (imdad@juniv.edu)

** Department of Electronics and Communications Engineering, East West University, 43 Mohakhali, Dhaka 1212, Bangladesh (ramin@ewubd.edu)
} 
conventional mobile cellular system, then the system is known as a voice-data integrated network [7-8].

For non-Markovian traffic, the situation is different. For example, in packet switching, the information/message, regardless of content, type, or structure is converted into suitably-sized blocks, called packets. The sequences of packets from different information sources can share the common trunk and arrival of these packets (variable-bit-rate data streams) upon which a switch /router is routed to the appropriate outgoing link. In case of an appropriate router (because of huge traffic) being available, the packets are buffered or queued. After some instant of time (variable amount of delay), the outgoing link becomes free and the packets are routed to appropriate directions.

In this paper, we consider dual mode terminals of a LAN of BUS topology, where each terminal can send packets using either a token bus or a carrier sense multiple access with collision detection (CSMA/CD) protocol. We consider the packet traffic of a LAN that follows the M/G/1 model, where a packet may experience infinite delay since the size of the buffer is infinite. If a similarly offered traffic is applied to a limited buffer system, for example the $\mathrm{M} / \mathrm{G} / 1$ (m) model, some packets will be lost.

According to teletraffic theory, the probability of occupancy by a full buffer is the probability of loss of packets. The probability of delay and cell/packet loss is prevalent but it is a cumbersome task to determine the traffic parameters of a combined packet traffic stream [9, 10]. In this paper, the probability states of $\mathrm{M} / \mathrm{G} / 1(\mathrm{~m})$ before normalization are evaluated and the corresponding analysis is presented in the next section. The triangular matrix of a two-dimensional Markov chain is built for token bus and CSMA/CD traffic. Finally, the triangular matrix is normalized and complete occupied states are selected. The sum of the complete occupied states gives the packet loss probability. Sometimes it is necessary to determine the cell loss probability of a finite buffer network, which is equivalent to a finite amount of delay of an infinite buffer network. The model used here can solve the condition of the determination of the length of the queue to keep the quality of service (QoS) equivalent to the delay of an infinite buffer case.

The paper is organized as follows: Section II deals with the theoretical analysis of determination of the mean delay of the Token BUS and the CSMA/CD traffic of the M/G/1 model. Section III provides the theoretical analysis of determination for the probability states and for the probability of cell loss rate of a finite buffer network. Section IV gives the results corresponding to a combined traffic model along with an example, and finally, Section V concludes the entire analysis.

\section{THE PACKet TRAFFic Of AN INFINITE Buffer}

\subsection{Token Ring}

In a token ring LAN, a special packet called a token (permission to access the ring) circulates among a number of terminals in a ring configuration as shown in Fig. 1. Terminals get the opportunity to seize the token sequentially. Once the terminal gets the token, the terminal converts it to a busy packet with a destination address. After receiving the packet, the destination node sends the acknowledgment to the source node. Receiving the acknowledgment, the sending node generates a new token to be used by another station.

Under the independent Poisson's process, the mean message arrival rate at queue is assumed 


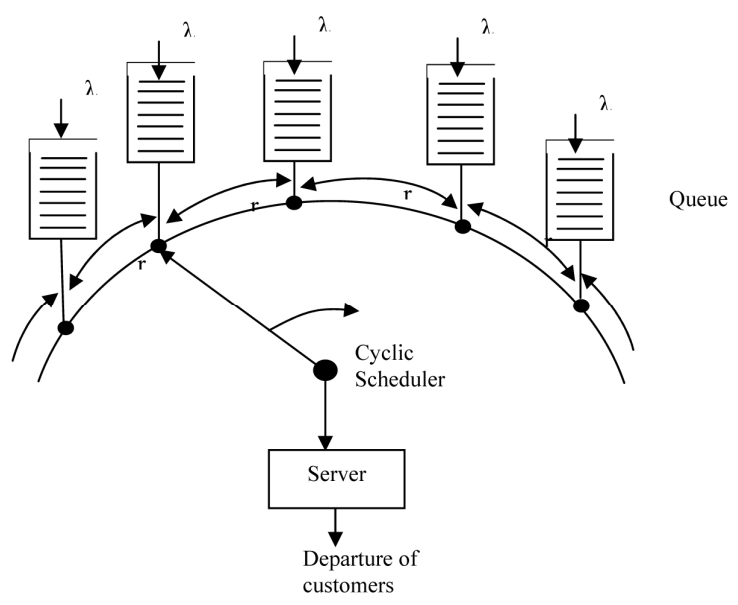

Fig. 1. Token Ring LAN

to be: $\lambda_{1}=\lambda_{2}=\lambda_{3}=\ldots \quad \ldots \quad \ldots=\lambda / N$, where $\lambda_{i}$ is the arrival rate of station $i$, and $N$ is the number of users. The switchover time is $r_{1}=r_{2}=r_{3}=\ldots \quad \ldots \quad \ldots=R / N=r$, where $r_{i}$ is the switchover time from queue $i$ to $i+1$ and $R=\sum_{i=1}^{N} r_{i}$. The mean waiting time (queuing delay) at the sending station is:

$$
E[W]=\frac{\delta^{2}}{2 r}+\frac{N r(1 \pm \rho / N)}{2(1-\rho)}+\frac{\rho E\left[S^{2}\right]}{2(1-\rho) E[S]},
$$

where $\delta^{2}$ is the variance of the switchover time, $\rho=\sum_{i=1}^{N} \rho_{i}<1$ is the traffic intensity under normalized condition, $\rho_{i}=\lambda_{i} E\left[S_{i}\right], E\left[S_{i}\right]$ is the mean service time of station $i$ that follows the general distribution, and $E[S]$ is the mean service time (packet length in time unit) expressed as $E[S]=\left(E\left[L_{p}\right]+L_{h}\right) / R=\rho / \lambda$, where $L_{p}$ and $L_{h}$ are the mean packet length and header length respectively.

For constant service time, we use $E\left[S^{2}\right]=E^{2}[S]$ and for exponential service time, $E\left[S^{2}\right]=2 E^{2}[S]$ is used. The average propagation delay is $E\left[T_{p}\right]=\tau / 2$; where $\tau$ is the round trip propagation delay. The propagation time $T_{p}$ is the time elapsed from the beginning of the transmission of the message until the arrival of the first bit of the message at the destination. The mean transfer delay is: $E[D]=E[W]+E[S]+E\left[T_{p}\right]$. In Eq. (1), the negative (-) sign in the numerator of the second term of the right-hand side is for the exhaustive service (the server serves a queue of work station transmitting all of the data, including the date received during the transmission, until there is no message left in that queue) and the positive $(+)$ sign for the gated service. (The server does a similar job only for the data that was waiting before the transmission began. In this type of service a gate is closed behind the waiting customer at the instant the server in that queue. The customers in front of the gate are served.) The transmission/service time $S$ is the time elapsed between the arrival of the first bit of the message at the destination and the arrival of the last bit. 


\subsection{Token Bus}

The operation for token bus protocol is similar to that of the token ring. Here, instead of a ring, bus topology is used and the stations are ordered in such a way that they form a logical ring. The typical ordering of stations on a bus (token bus) is shown in Fig. 2. Let the length of the bus be $l$ and corresponding end-to-end propagation delay be $\tau$. Furthermore, let us consider that the mean message arrival rate at the queue according to the independent Poisson's process is: $\lambda / N$, as mentioned in the previous subsection. Similarly, the switchover time is: $r=R / N$. For a token passing bus, we have $r=\tau / 3+c, \delta^{2}=\tau^{2} / 18$, the mean propagation delay is $E\left[T_{p}\right]=\tau / 3$, where $c=\left(L_{t}+L_{b}\right) / R, L_{t}$ is the length of the token in bits and $L_{b}$ is the bit delay by each station.

If the mean transfer delay is $D$, including waiting time $W$ (queuing delay) at the sending station, if the service time of the message is $S$ and if the propagation delay is $T_{p}$, then the average of $D$ can be written as:

$$
E[D]=\frac{\tau^{2}}{36(\tau / 3+c)}+N(\tau / 3+c) \frac{(1 \pm \rho / N)}{2(1-\rho)}+\frac{\rho E\left[S^{2}\right]}{2(1-\rho) E[S]}+E[S]+\frac{\tau}{3}
$$

In Eq. (2), the minus (-) sign is for exhaustive service and the plus (+) sign is for the gated service.

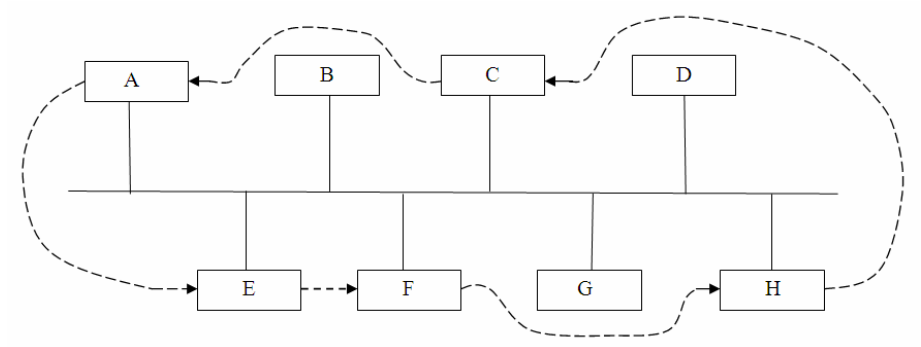

Fig. 2. A Token Bus LAN

\subsection{CSMA/CD Bus}

In CSMA/CD, a node starts its transmission after sensing that there is no carrier in the bus, therefore, the collision of packets from simultaneous users are reduced. If the node finds the bus busy then it waits for a random amount of time and re-sensed the channel. If a node experiences collision during transmission it stops the transmission and waits for a random amount of time for retransmission.

Considering the $\mathrm{M} / \mathrm{G} / 1$ queuing source, the mean delay will be:

$$
\begin{gathered}
E[D]=\frac{\lambda\left(E\left[S^{2}\right]+(4 e+2) \tau E[S]+5 \tau^{2}+4 e(2 e-1) \tau^{2}\right)}{2(1-\lambda[E[S]+\tau+2 e \tau])} \\
-\frac{\left(1-e^{-2 \lambda \tau}\right)(e+\lambda \tau-3 \lambda \tau e)}{\lambda e\left\{F(\lambda) e^{-(1+\lambda \tau)}+e^{-2 \lambda \tau}-1\right\}}+2 \tau e+E[S]+\frac{\tau}{3},
\end{gathered}
$$


where $F(\lambda)$ is the Laplace transform of the message transmission time distribution $f(t)$ and can be expressed as:

$$
F(\lambda)=\int_{0}^{\infty} f(t) e^{-\lambda t} d t
$$

For constant message lengths, it can be shown that $F(\lambda)=e^{-\rho}$ and $E\left[S^{2}\right]=E^{2}[S]$, where $\rho=\lambda E[S]$ and $1 / e=0.368$. For exponentially distributed message lengths, $F(\lambda)=1 /(1+\rho)$ and $E\left[S^{2}\right]=2 E^{2}[S]$.

Entire analysis of the above network is done for the case of an infinite queue so the packet/cell will experience only a delay but no cells will be lost. We will check the cell loss rate of the above network for a finite queuing model.

\section{Connection Oriented Packet Switching Of M/G/1(m) Traffic}

Let $\lambda_{j}, h_{j}, V_{j}$, and $y_{j}$ be the call arrival rate, the mean call holding (connection) time, data speed, and the data activity rate for class $j \in J$ respectively. The input traffic load $a$ and the utilization $\rho_{c o}$ of the transmission line are given by

$$
\begin{aligned}
a & =\sum_{j \in J} \lambda_{j} h_{j}, \\
\rho_{c o} & =(1-B) \frac{L_{c}}{L_{p}} \frac{1}{c} \sum_{j \in J} \lambda_{j} h_{j} V_{j} y_{j},
\end{aligned}
$$

where $B$ is the call blocking probability, $L_{c}$ is the cell length (53 bytes for ATM), $L_{p}$ is the payload length (48 bytes for an asynchronous transfer mode (ATM)), and $c$ is the transmission speed. From Erlang's loss formula, the cell loss rate is given with the following expression:

$$
B=\frac{a^{s}}{s !} / \sum_{i=0}^{s} \frac{a^{i}}{i !}
$$

where $s$ is the number of virtual channels (VCs) assigned to the transmission line. According to [11] for $\mathrm{M} / \mathrm{G} / 1$ system, we have the steady probability state:

$$
\Pi_{j}^{*}=p_{j} \Pi_{0}^{*}+\sum_{k=1}^{j+1} p_{j-k+1} \Pi_{k}^{*} ; \mathrm{j}=0,1,2, \ldots
$$

where $p_{j}$ is the probability that $j$ calls arrive during the service time.

The mean cell delay of $\mathrm{M} / \mathrm{G} / 1$ traffic is: 


$$
W=\frac{a}{(1-a)} \frac{h}{2}\left(1+C^{2}\right)
$$

where $a=\lambda h, \lambda$ is the packet arrival rate, $h$ is the service time, and the parameter $C$ is defined after Eq. ((10).

For the $\mathrm{M} / \mathrm{G} / 1(\mathrm{~m})$ system, $\Pi_{j}^{*}=0$ for $j \geq m+1$ and Eq. (7) takes the following recurrence form:

$$
\Pi_{j+1}^{*}=\left(\Pi_{j}^{*}-p_{j} \Pi_{0}^{*}-\sum_{k=1}^{j} p_{j-k+1} \Pi_{k}^{*}\right) p_{0}^{-1} ; \mathrm{j}=0,1,2, \ldots, \mathrm{m}-1
$$

Taking $C_{j}=\Pi_{j}^{*} / \Pi_{0}^{*}$, we get:

$$
C_{j+1}=\left(C_{j}-p_{j}-\sum_{k=1}^{j} p_{j-k+1} C_{k}\right) p_{0}^{-1} ; \mathrm{j}=0,1,2, \ldots, \mathrm{m}-1
$$

Let $C=\sum_{j=0}^{m} C_{j}$ with $C_{0}=1$ and by combining the above equations, we obtain:

$$
\Pi_{j}=\Pi_{j}^{*}=P_{j}=\frac{C_{j}}{1+a C}
$$

The cell loss rate is:

$$
B=P_{m+1}=1-\sum_{j=0}^{m} P_{j}=1-\sum_{j=0}^{m} \frac{C_{j}}{1+a C}=1-\frac{C}{1+\rho_{c o} C} .
$$

Form the Little formula, the mean cell delay $W_{c o}$ can be written as:

$$
W_{c o}=\frac{h_{c}}{1+\rho_{c o} C}\left\{m C-\rho_{c o}^{-1} \sum_{k=1}^{m}(m-k+1) C_{k}\right\},
$$

where $h_{c}=L_{c} / c$ is the cell transmission time and $p_{k}=\rho_{c o}^{k} e^{-\rho_{c o}} / k$ !. For a very small value of $B$ or large value of $m$, the approximate formula of $W_{c o}$ can be derived to be:

$$
W_{c o}=\left(\frac{\rho_{c o}(1-B)-B-2 m B}{2\left(1-\rho_{c o}\right)}\right) h_{c} .
$$

Equation (14) gives the approximate expression for the mean cell delay and can be derived using Little's formula and taking the mean residual service time $h_{c} / 2$ and the waiting probabil- 
ity $\sum_{j=1}^{m} \Pi_{j}^{*}=1-\Pi_{0}^{*}-B=\rho_{c o}(1-B)-B$. To reduce the computational complexity, the above approximate equation, Eq. (14), for the mean cell delay, can be used instead of using Eq. (13) for a network of large buffer.

\section{RESULtS}

Fig. 3 shows the profile for carried traffic intensity (Erls/trunk) against the mean delay in mille-second (ms) for both CSMA/CD BUS and Token BUS by taking the length of the payload part of the packet as a parameter. For the length of the payload of a packet of 500 bits and a delay of $1 \mathrm{~ms}$, the carried traffic intensity of CSMA/CD BUS is $0.53 \mathrm{Erls} / \mathrm{trunk}$ and that of the Token BUS is 0.66 Erls/trunk. The carried traffic for the two cases are decreased to 0.3 and 0.33 respectively when the length of the payload is increased to 800 bits.

Now our aim is to determine the cell loss rate of the finite queuing system for the offered traffic intensity of $0.53 \mathrm{Erls} /$ trunk of the CSMA/CD BUS and 0.66Erls/trunk for that of the Token BUS. This cell loss rate will be equivalent to the delay of $1 \mathrm{~ms}$ for an infinite queuing system. Let us now consider the length of the queue of a router to be 7 and considering the arrival of two types of M/G/1(7) traffic. Let the vector of probability states of CSMA/CD BUS be $\mathbf{Q}$ (for 0.53 Erls/trunk) and that of Token BUS be $\mathbf{P}$ (for 0.66 Erls/trunk). Applying the traffic model of $\mathrm{M} / \mathrm{G} / 1(\mathrm{~m})$ of Sec. III, we determine the probability states for $C_{j}$ (before normalization) and put them in the following vectors:

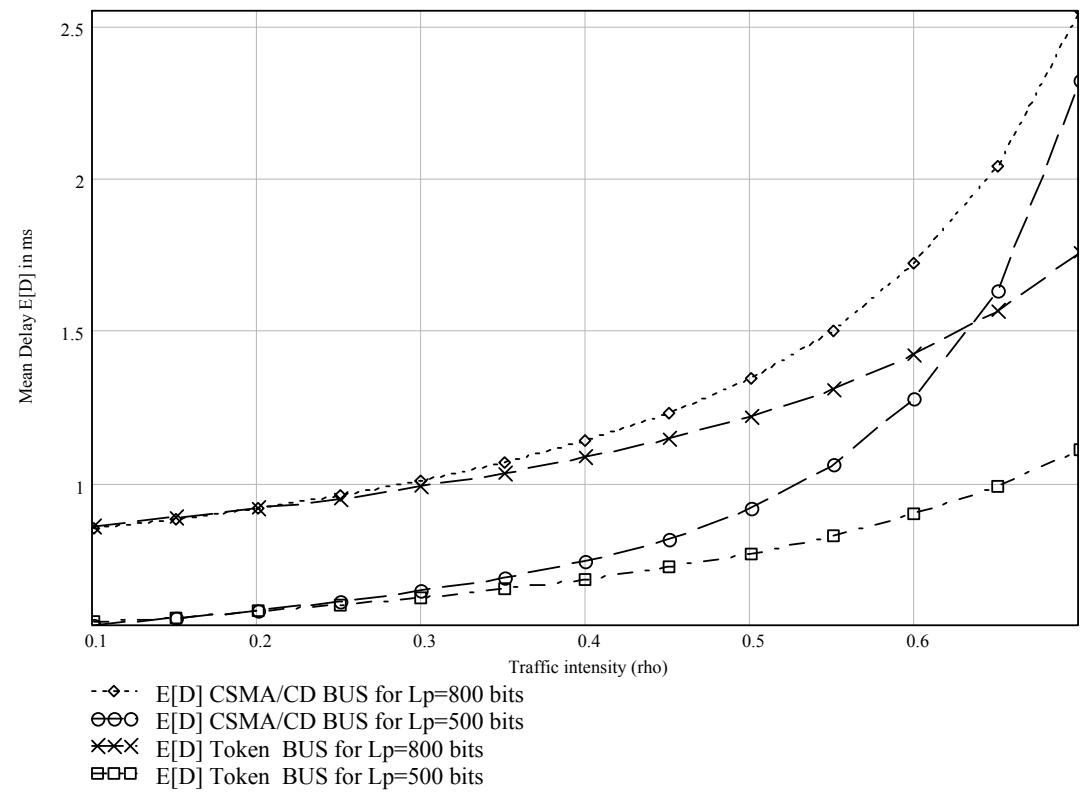

Fig. 3. Variation of mean delay against carried traffic 


\begin{tabular}{|c|c|c|}
\hline $\mathbf{P}=[1.00000000$ & 0.93400000 & 0.53100000 \\
\hline 0.25500000 & 0.11700000 & 0.05300000 \\
\hline 0.02300000 & $9.5600 \mathrm{E}-03]$ & \\
\hline
\end{tabular}

and

$\begin{array}{rlr}\mathbf{Q}=[1.00000000 & 0.69900000 & 0.28600000 \\ 0.09600000 & 0.03000000 & 8.8900 \mathrm{E}-03 \\ 2.2500 \mathrm{E}-03 & 1.6800 \mathrm{E}-04] . & \end{array}$

The above vectors, after normalization, become:

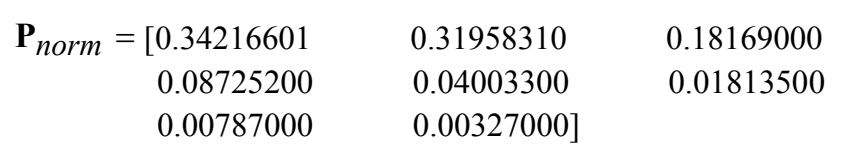

and

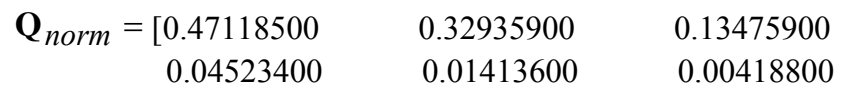

$$
\begin{aligned}
& 0.00106000 \quad 7.9100 \mathrm{E}-05] \text {. }
\end{aligned}
$$

Now the vectors $\mathbf{P}$ and $\mathbf{Q}$ can be applied to a two-dimensional traffic model of the tabular form of [12] as shown in Table 1(a) and (b) respectively.

From the above vectors and tables, we can easily determine the individual and combined system blocking probability. For only CSMA/CD BUS traffic, the blocking probability (from normalization vector $\mathbf{P}$ ) is found to be $B_{1}=0.00327$. Similarly, only for Token BUS traffic, the blocking probability (from normalization vector $\mathbf{Q}$ ) is found to be $B_{2}=7.906 \mathrm{E}-05$.

Let us now determine the overall/combined cell blocking probability when both types of traffic exist simultaneously on a BUS. The work can be done in the tabular form of a twodimensional traffic model of [13] as shown in Table 1. In Table 1(a) and Table 1(b), the probability states are determined before and after normalization. The sum of the complete occupied states provides the overall cell blocking probability. Thus, the overall blocking probability is found to be:

$$
\begin{aligned}
\mathrm{B}_{0} & =2.72 \mathrm{E}-05+3.41 \mathrm{E}-04+7.66 \mathrm{E}-04+1.24 \mathrm{E}-03+1.82 \mathrm{E}-03+2.46 \mathrm{E}-03+2.61 \mathrm{E}-03+1.55 \mathrm{E}-03 \\
& =1.08 \mathrm{E}-03
\end{aligned}
$$

which is seen to be greater than the sum of the individual blocking probabilities. This happens because of the statistical distribution of the offered traffic. 
Table 1. (a) Before Normalization, (b) After Normalization

(a)

\begin{tabular}{|c|c|c|c|c|c|c|c|c|c|}
\hline $\mathrm{Q}_{7}$ & $\begin{array}{l}1.68 \\
\text { E-04 } \\
\end{array}$ & $\begin{array}{l}1.68 \\
\text { E-04 } \\
\end{array}$ & & & & & & & \\
\hline $\mathrm{Q}_{6}$ & $\begin{array}{l}2.25 \\
\text { E- } 03\end{array}$ & $\begin{array}{l}2.25 \\
\text { E- } 03\end{array}$ & $\begin{array}{l}2.10 \\
\text { E-03 }\end{array}$ & & & & & & \\
\hline $\mathrm{Q}_{5}$ & $\begin{array}{l}8.89 \\
\text { E- } 03\end{array}$ & $\begin{array}{l}8.89 \\
\text { E-03 }\end{array}$ & $\begin{array}{l}8.30 \\
\text { E- } 03\end{array}$ & $\begin{array}{l}4.72 \\
\mathrm{E}-03\end{array}$ & & & & & \\
\hline $\mathrm{Q}_{4}$ & 0.03 & $\begin{array}{l}3.00 \\
\text { E-02 }\end{array}$ & $\begin{array}{l}2.80 \\
\text { E- } 02\end{array}$ & $\begin{array}{l}1.59 \\
\text { E-02 }\end{array}$ & $\begin{array}{l}7.65 \\
\text { E- } 03\end{array}$ & & & & \\
\hline $\mathrm{Q}_{3}$ & 0.096 & $\begin{array}{l}9.60 \\
\text { E-02 }\end{array}$ & $\begin{array}{l}8.97 \\
\text { E-02 }\end{array}$ & $\begin{array}{l}5.10 \\
\text { E- } 02\end{array}$ & $\begin{array}{l}2.45 \\
\text { E-02 }\end{array}$ & $\begin{array}{l}1.12 \\
\text { E-02 }\end{array}$ & & & \\
\hline $\mathrm{Q}_{2}$ & 0.286 & $\begin{array}{l}2.86 \\
\text { E-01 }\end{array}$ & $\begin{array}{l}2.67 \\
\text { E-01 }\end{array}$ & $\begin{array}{l}1.52 \\
\text { E-01 }\end{array}$ & $\begin{array}{l}7.293 \\
\text { E-02 }\end{array}$ & $\begin{array}{l}3.35 \\
\text { E-02 }\end{array}$ & $\begin{array}{c}1.52 \\
\text { E-02 }\end{array}$ & & \\
\hline $\mathrm{Q}_{1}$ & 0.699 & $\begin{array}{l}6.99 \\
\text { E-01 }\end{array}$ & $\begin{array}{l}6.53 \\
\text { E-01 }\end{array}$ & $\begin{array}{l}3.71 \\
\text { E-01 }\end{array}$ & $\begin{array}{r}1.78 \\
\text { E-01 }\end{array}$ & $\begin{array}{l}8.18 \\
\text { E-02 } \\
\end{array}$ & $\begin{array}{l}3.71 \\
\text { E-02 } \\
\end{array}$ & $\begin{array}{l}1.61 \\
\text { E-02 }\end{array}$ & \\
\hline \multirow[t]{3}{*}{$\mathrm{Q}_{0}$} & 1 & $\begin{array}{c}1.00 \\
\mathrm{E}+00\end{array}$ & $\begin{array}{l}9.34 \\
\text { E-01 }\end{array}$ & $\begin{array}{l}5.31 \\
\text { E-01 }\end{array}$ & 0.255 & 0.117 & 0.053 & 0.023 & $\begin{array}{l}9.56 \\
\text { E- } 03\end{array}$ \\
\hline & & 1 & 0.934 & 0.531 & 0.255 & 0.117 & 0.053 & 0.023 & $\begin{array}{r}9.56 \\
\text { E-03 } \\
\end{array}$ \\
\hline & & $\mathrm{P}_{0}$ & $\mathrm{P}_{1}$ & $\mathrm{P}_{2}$ & $\mathrm{P}_{3}$ & $\mathrm{P}_{4}$ & $\mathrm{P}_{5}$ & $\mathrm{P}_{6}$ & $\mathrm{P}_{7}$ \\
\hline
\end{tabular}

(b)

\begin{tabular}{|c|c|c|c|c|c|c|c|c|c|}
\hline $\mathrm{Q}_{7}$ & $\begin{array}{l}1.68 \\
\text { E-04 }\end{array}$ & $\begin{array}{l}2.72 \\
\text { E- } 05\end{array}$ & & & & & & & \\
\hline $\mathrm{Q}_{6}$ & $\begin{array}{l}2.25 \\
\text { E-03 }\end{array}$ & $\begin{array}{l}3.65 \\
\text { E-04 }\end{array}$ & $\begin{array}{l}3.41 \\
\text { E-04 }\end{array}$ & & & & & & \\
\hline $\mathrm{Q}_{5}$ & $\begin{array}{l}8.89 \\
\text { E-03 }\end{array}$ & $\begin{array}{l}1.44 \\
\text { E-03 }\end{array}$ & $\begin{array}{l}1.35 \\
\text { E-03 }\end{array}$ & $\begin{array}{l}7.66 \\
\text { E-04 }\end{array}$ & & & & & \\
\hline $\mathrm{Q}_{4}$ & 0.03 & $\begin{array}{l}4.87 \\
\text { E- } 03\end{array}$ & $\begin{array}{l}4.54 \\
\text { E-03 } \\
\end{array}$ & $\begin{array}{l}2.58 \\
\mathrm{E}-03 \\
\end{array}$ & $\begin{array}{l}1.24 \\
\text { E-03 } \\
\end{array}$ & & & & \\
\hline $\mathrm{Q}_{3}$ & 0.096 & $\begin{array}{l}1.56 \\
\text { E-02 }\end{array}$ & $\begin{array}{l}1.45 \\
\text { E-02 }\end{array}$ & $\begin{array}{l}8.27 \\
\text { E- } 03\end{array}$ & $\begin{array}{l}3.97 \\
\text { E-03 }\end{array}$ & $\begin{array}{l}1.82 \\
\text { E- } 03\end{array}$ & & & \\
\hline $\mathrm{Q}_{2}$ & 0.286 & $\begin{array}{l}4.64 \\
\text { E-02 } \\
\end{array}$ & $\begin{array}{l}4.33 \\
\text { E-02 } \\
\end{array}$ & $\begin{array}{l}2.46 \\
\mathrm{E}-02 \\
\end{array}$ & $\begin{array}{l}1.18 \\
\text { E-02 } \\
\end{array}$ & $\begin{array}{l}5.43 \\
\text { E- } 03 \\
\end{array}$ & $\begin{array}{l}2.46 \\
\text { E-03 } \\
\end{array}$ & & \\
\hline $\mathrm{Q}_{1}$ & 0.699 & $\begin{array}{l}1.13 \\
\text { E- } 01\end{array}$ & $\begin{array}{l}1.06 \\
\text { E-01 }\end{array}$ & $\begin{array}{l}6.02 \\
\text { E-02 }\end{array}$ & $\begin{array}{l}2.89 \\
\text { E-02 }\end{array}$ & $\begin{array}{l}1.33 \\
\text { E-02 }\end{array}$ & $\begin{array}{l}6.01 \\
\text { E-03 }\end{array}$ & $\begin{array}{l}2.61 \\
\text { E-03 }\end{array}$ & \\
\hline \multirow[t]{3}{*}{$\mathrm{Q}_{0}$} & 1 & $\begin{array}{l}1.62 \\
\text { E-01 }\end{array}$ & $\begin{array}{l}1.51 \\
\text { E-01 }\end{array}$ & $\begin{array}{l}8.61 \\
\text { E-02 }\end{array}$ & $\begin{array}{l}4.14 \\
\text { E-02 }\end{array}$ & $\begin{array}{l}1.90 \\
\text { E- } 02\end{array}$ & $\begin{array}{l}8.60 \\
\text { E-03 }\end{array}$ & $\begin{array}{l}3.73 \\
\text { E- } 03\end{array}$ & $\begin{array}{l}1.55 \\
\text { E- } 03\end{array}$ \\
\hline & & 1 & 0.934 & 0.531 & 0.255 & 0.117 & 0.053 & 0.023 & $\begin{array}{l}9.56 \\
\text { E- } 03\end{array}$ \\
\hline & & $\mathrm{P}_{0}$ & $\mathrm{P}_{1}$ & $\mathrm{P}_{2}$ & $\mathrm{P}_{3}$ & $\mathrm{P}_{4}$ & $\mathrm{P}_{5}$ & $\mathrm{P}_{6}$ & $\mathrm{P}_{7}$ \\
\hline
\end{tabular}

\section{Conclusion}

The paper deals with the two-dimensional packet traffic of a M/G/1(m) case. Usually, the performance of two-dimensional packet traffic for a general service-time distribution case is analyzed by incorporating the Markov modulated Poisson's process (MMPP) model with M/G/1(m) traffic. Our present analysis has the flexibility of enhancement for a multi-dimensional dissimilar bandwidth case of packet traffic even for complete sharing or partitioning a call admission scheme. It has been demonstrated that the packet dropping probability of the combined traffic is 
much larger than the individual service case and is even larger than the sum of the individual service cases. This happens because of the statistical distribution of the occupancy of the states. This work can be extended for the case of a dissimilar bandwidth or three-dimensional traffic or even for star LAN. The work will be helpful for a network planar to select the capacity of the link for a LAN to maintain the desired QoS in multi-dimensional traffic services.

\section{REFERENCES}

[1] D. Bear, Principle of Telecommunication Traffic Engineering, Second Edition, Peter Peregrinus Ltd., Hertfordshire, U.K., 1988.

[2] Md. I. Islam, M. Q. Maula and L. J. Rozario, "Analysis of two dimensional limited source and mixed traffic model for a BTS of a small mobile cellular network," Proceedings of the $4^{\text {th }}$ International Conference on Computers and Information Technology (ICCIT), Dhaka, December 2001.

[3] P. Srisukpibul, "Traffic Measurement on a Cellular Mobile Network," Masters Thesis, Division of Telecommunications, AIT, Bangkok, Thailand, 1997.

[4] Paul Fitzpatrick, Cheng Siong Lee and Bob Warfiled, "Teletraffic Performance of Mobile Radio Networks with Hierarchical Cells and Overflow," IEEE J. Select. Areas Commun., Vol.15, No.8, 1997, pp.1549-57.

[5] Kwan L. Yeung and Sanjib Nanda, "Channel Management in Micro/Macro Cellular Radio Systems," IEEE Trans. Veh. Technol., Vol.45, No.4, 1996, pp.14-23.

[6] M. I. Islam and S. Hossain, "An analytical model of traffic performance of mobile cellular network in underlay overlay cell system," Proceedings of the $6^{\text {th }}$ International Conference on Computers and Information Technology (ICCIT), Dhaka, Bangladesh, Dec. 2003.

[7] M. Mahdavi, R.M. Edwards and S.R. Cvetkovic, "Polycy Enhancement of Traffic in TDMA Hybrid Switched Integrated Integrated Voice/Data Cellular Mobile Communications Systems," IEEE Commun. Lett., Vol.5, No.6, 2004, pp.242-244.

[8] Bin Li, Lizhong, Bo Li and Xi-Ren Cao, "Call admission control for voice/data integrated cellular networks: performance analysis and comparative study," IEEE J. Select. Areas Commun., Vol.22, No.4, 2004, pp.706-718.

[9] W. Bux, "Performance issues in local area networks," IBM Syst. Journal, Vol.23, No.4, 1984, pp.351-374.

[10] T. Supot and H. Akimaru, "A performance evaluation for heterogeneous bus CSMA/CD LANs," IEICE Trans. Commun., Vol.E74-B, No.9, 991, pp.2721-2727.

[11] Md. Imdadul Islam, Md. Shahriar Karim, J. K. Das and M. R. Amin, "Evaluation of Traffic Parameters of Multidimensional Traffic of a Combined Link Using a Tabular Method," Proceedings of the $11^{\text {th }}$ International Conference on Computers and Information Technology (ICCIT), KUET, Bangladesh, December 2008.

[12] Haruo Akimaru, Marion R. Finley and Kyoko Yamori "A Practical Dimensioning Method for ATM System," IEEE Trans. Commun., Vol.47, No.2, 1999, pp.311-315.

[13] S. Hossain and Imdadul Islam, "Analysis of SDMA PCT-II Traffic for Duplicated First Case: A Theoretical Study," International Conference on Wireless Communications, Networking and Mobile Computing, Wuhan, China, September 2005. 


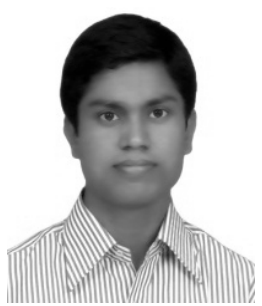

Md. Syeful Islam recieved his B.Sc. degree in Computer Science and Engineering from Jahangirnagar University in Dhaka, Bangladesh in 2011. Currently, he is working as a software consultant in the Micro-Finance Solutions Department of Southtech Limited in Uttara, Dhaka, Bangladesh.

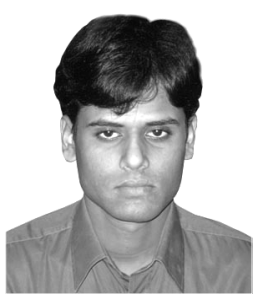

Md. Rezaur Rahman received his B.Sc. degree in Computer Science and Engineering from Jahangirnagar University in Dhaka, Bangladesh in 2011. He is currently working as a Lecturer in the Department of Computer Science and Engineering at the Daffodil Institute of Information Technology in Dhaka, Bangladesh.

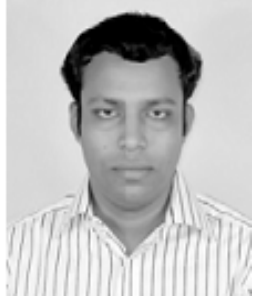

Anupam Roy received his B.Sc. in Computer Science and Engineering from Jahangirnagar University in Savar, Dhaka, Bangladesh in 2007. He is now pursuing his M.Sc. in Engineering at the same department. He worked for a few months as a General Software Developer at MFASIA LTD (A joint venture company between Bangladesh and England) and as a Java Programmer at ATI LTD in Dhaka, Bangladesh. He is now working as a Programmer at BJIT LTD (A joint venture company between Bangladesh and Japan) in Dhaka, Bangladesh.

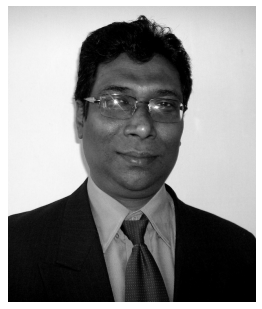

Md. Imdadul Islam has received his B.Sc. and M.Sc. in Electrical and Electronic Engineering from the Bangladesh University of Engineering and Technology in Dhaka, Bangladesh in 1993 and 1998 respectively and completed his Ph.D. degree in 2010 at the Department of Computer Science and Engineering at Jahangirnagar University in Dhaka, Bangladesh in the field of network traffic engineering. He is now working as a Professor in the Department of Computer Science and Engineering at Jahangirnagar University in Savar, Dhaka, Bangladesh. Previously, he worked as an Assistant Engineer at Sheba Telecom (Pvt.) LTD (A joint venture company between Bangladesh and Malaysia, for mobile cellular and WLL) from Sept. '94 to July '96. He has very good field experience in the installation of Radio Base Stations and Switching Centers for WLL. His research fields are network traffic, wireless communications, wavelet transform, OFDMA, WCDMA, adaptive filter theory, ANFIS, and array antenna systems. He has more than a hundred research papers in national and international journals and conference proceedings. 


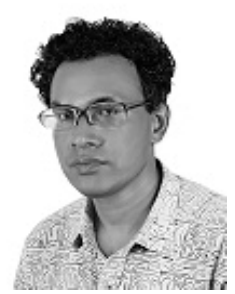

M. R. Amin received his B.Sc. and M.Sc. degrees in Physics from Jahangirnagar University in Dhaka, Bangladesh in 1984 and 1986 respectively and his Ph.D. degree in Plasma Physics from the University of St. Andrews in the U. K. in 1990. $\mathrm{He}$ is a Professor of Electronics and Communications Engineering at East West University in Dhaka, Bangladesh. He served as a Post-Doctoral Research Associate in Electrical Engineering at the University of Alberta, Canada, during 19911993. He was an Alexander von Humboldt Research Fellow at the Max-Planck Institute for Extraterrestrial Physics in Garching/Munich, Germany during 19971999. Dr. Amin was awarded the Commonwealth Postdoctoral Fellowship in 1997. Besides these, he has also received several awards for his research, including the Bangladesh Academy of Science Young Scientist Award for the year 1996 and the University Grants Commission Young Scientist Award for 1996. He is a member of the IEEE. His current field of research is wireless communications and networks. 